\title{
Effect of Spirulina platensis on the quality and antioxidants characteristics of ice cream
}

\author{
Petya Boyanova $^{1 *}$, Dilyana Gradinarska ${ }^{2}$,Valentina Dobreva ${ }^{3}$, Petar Panayotov ${ }^{1}$, Maria Momchilova ${ }^{4}$, and Gabor \\ Zsivanovits $^{4}$ \\ ${ }^{1}$ Department of Milk and Dairy Products Technology, Technological Faculty, University of Food Technologies, Plovdiv, Bulgaria \\ ${ }^{2}$ Department of Meat and Fish Technology, Technological Faculty, University of Food Technologies, Plovdiv, Bulgaria \\ ${ }^{3}$ Department of Engineering Ecology, Economical Faculty, University of Food Technologies, Plovdiv, Bulgaria \\ ${ }^{4}$ Division of Food Technologies, Food Research and Development Institute, Agricultural Academy of Bulgaria, Plovdiv, Bulgaria
}

\begin{abstract}
Spirulina platensis is a cyanobacterium (blue-green algae) that grows in alkaline waters. In food industry, Spirulina's phycocyanin is used as a natural colorant and stabilizer. The influence of three different concentrations of Spirulina platensis $(0.5 \%, 1 \%$ and $1.5 \%)$ on physicochemical, textural, antioxidant and sensory parameters of ice cream was studied. It was found that with increasing spirulina concentration, the overrun increases from $30.6 \%$ (IC-0) to $48.3 \%$ (IC-3). The analysis of texture profile (hardness, adhesiveness, cohesiveness, gumminess) of samples showed a statistically significant difference $(\mathrm{p}<0.05)$ between reported values for control sample (IC-0) and the samples with spirulina. Ice cream samples supplemented with spirulina differed with significant increase $(\mathrm{p}<0.05)$ in antioxidant activity from $2.8 \pm 2.2$ $\mathrm{mM}$ TE/100 g DW (control sample) to $112.9 \pm 4.1 \mathrm{mM} \mathrm{TE} / 100 \mathrm{~g}$ DW (IC-3). The addition of Spirulina platensis in ice cream mixture improves its quality and antioxidant properties.
\end{abstract}

\section{Introduction}

Nowadays people pay more and more special attention to nutritional and health benefits of food products they consume. In response of demand for food with health protective properties, producers invest in amelioration of technological recipes by implementation of natural bioactive molecules like vitamins, antioxidants, essential fatty acids and others.

Spirulina platensis is filamentous cyanobacterium microalgae composed primary of proteins (55-70\%), carbohydrates (15-20\%) and lipids (approximately 7\%) $[1,2,3]$. It is also rich in vitamins, minerals and other bioactive compounds like carotenoids, chlorophylls and phycocyanin the last of which is recognized as important antioxidant agent [4]. Spirulina is recognized as a safe and non-toxic food supplement according to the Food and Drug Administration (FDA). The assessment of FDA is based on the nutritional and antioxidant properties of spirulina due to its chemical composition and biological active ingredients [5].

Spirulina platensis is regarded by many authors as attractive supplement for bio-fortification in foods $[6,7$, 8] and pharmaceuticals. Agustiani et al. [9] highlighted that antioxidant and anti-inflammatory properties of spirulina's bioactive compounds make it usable in functional food production. Numerous clinical studies proving the therapeutic and preventive effect of Spirulina platensis in many diseases has been reported in literature $[10,11,12,13]$.
Agustini et al. [9] established that some bioactive compounds of spirulina (carotenoids, chlorophyll, phycocyanin) are not resistant to heat treatment, so why the processing techniques for its application in foods must be considered. In this sense, one of foods that can be supplemented with spirulina is the ice cream. Ice cream is sweet frozen dairy product appreciated by many people because of its soft texture and cold sensation in the month [14].

The aim of the present research was to investigate and evaluate the effect of three different concentrations of Spirulina platensis $(0.5,1.0$ and $1.5 \%)$ on the antioxidant, physicochemical and textural properties of ice cream.

\section{Material and methods}

\subsection{Formulation of the ice cream mixture}

Spirulina platensis powder was provided by the company Magic Rose Ltd., Bulgaria. 975 g of UHT cow's milk (3.2\% fat), $307 \mathrm{~g}$ of cream (38\% fat), $210 \mathrm{~g}$ of sucrose, 7.5 $\mathrm{g}$ of gelatin and mint flavor were used to obtain $1.5 \mathrm{~kg}$ of ice cream mixture with a fat content of $10 \%$.

The amount of gelatin was added after heating the mixture of milk, cream and sugar at $85^{\circ} \mathrm{C}$, then homogenized for $10 \mathrm{~min}$ and kept for maturation at $6^{\circ} \mathrm{C}$ for $17 \mathrm{~h}$

After the cold maturation, spirulina powder was added in concentrations of $0.5 \%$ (IC-1), $1.0 \%$ (IC-2) and $1.5 \%$

\footnotetext{
* Corresponding author: petyabboyanova@gmail.com
} 
(IC-3). These concentrations were chosen in relation of desired intensity of green color of samples.

The freezing of ice cream base continued for $40 \mathrm{~min}$ in an ice cream machine (Gelato Chef 2200, $150 \mathrm{~W}, 1.5$ L). Then, samples were transferred to a freezer and stored at $-18^{\circ} \mathrm{C}$ for hardening. Ice cream prepared without spirulina was used as a control sample (IC-0).

\subsection{Determination of antioxidant activity and total phenolic compounds of spirulina powder and ice cream samples}

\subsubsection{Extraction}

Spirulina powder and ice cream samples (IC-0, IC-1, IC2 , IC-3) were extracted with $80 \%$ methanol $(1: 5 \mathrm{w} / \mathrm{v})$ in an ultrasonic bath VWR (Malaysia) with frequency 45 $\mathrm{kHz}$, power $30 \mathrm{~W}-\left(\mathrm{UAE} 45 \mathrm{kHz}\right.$ ) for $20 \mathrm{~min}$ at $35^{\circ} \mathrm{C}$. The extraction was performed in triplicate.

The obtained extract was filtered and used or determination of total phenolic content (TPC) and antioxidant activity.

\subsubsection{Total phenolic content (TPC)}

The total phenolic content (TPC) was analyses with spectrophotometric method, based on chemical reaction with Folin-Ciocalteu reagent. The absorbance was measured at $\lambda=765 \mathrm{~nm}$ (Campec M107, SpectronicCamspec, Ltd., Leeds, UK). Total phenolic content was determined using a standard gallic acid.

Obtained results were presented in $\mathrm{mg}$ of gallic acid equivalents (GAE) per $100 \mathrm{~g}$ dry weight (mg GAE/100 g DW), using a calibration curve $\mathrm{y}=12.557 \mathrm{x}-0.0871$, linear in the range of $0.02-0.10 \mathrm{mg}$ [15].

\subsubsection{Antioxidant activity}

Antioxidant activity was evaluated with CUPRAC assay. The performance of methodology is according to Ivanov et al. (2012) [15]. Absorbance was measured at $\lambda=450 \mathrm{~nm}$ (CamSpec M107, Spectronic-Camspec, Ltd., Leeds, UK). Antioxidant activity was expressed in $\mathrm{mM}$ equivalent of Trolox (TE) per $100 \mathrm{~g}$ dry weight (mM TE/100 g DW) by using calibration curve, built in the range of $0.05-0.5 \mathrm{mM}$ Trolox.

\subsection{Physicochemical analyse of the ice cream samples}

Titratable acidity (TA) of samples was determined titrating $5 \mathrm{~g}$ of ice cream with $0.1 \mathrm{~N} \mathrm{NaOH}$, using an indicator of $1 \%$ phenolphthalein solution until a pale pink color appeared. The sample $(5 \mathrm{~g})$ is pre-diluted with $30 \mathrm{ml}$ of distilled water. In the case of colored ice cream (ice cream with spirulina), the sample $(5 \mathrm{~g})$ is pre-diluted with $80 \mathrm{ml}$ of distilled water. The titratable acidity is expressed in Thörner degrees $\left({ }^{\circ} \mathrm{T}\right)$ and is calculated by the formula:

$$
\mathrm{TA}\left({ }^{\circ} \mathrm{T}\right)=\mathrm{V}_{\mathrm{NAOH}} \mathrm{x} 20
$$

$\mathrm{pH}$ values were measured with $\mathrm{pH}$-meter (model InoLab pH 720, WTW GmbH, Germany), connected with pH combination electrode (SenTix 81, WTW GmbH, Germany).

Total protein content was determined by the Kjeldahl method using a conversion factor of 6.38 to present the nitrogen content in protein concentration.

The humidity was analyses with moisture analyser (model XM50, Kern, Germany) equipped with halogen heating system. Three $g$ of melted ice cream sample were dried at $102 \pm 2{ }^{\circ} \mathrm{C}$ to constant weight.

Dry matter (DM) of samples was calculated according to the following formula:

$$
\text { Dry matter }(\%)=100-\text { Humidity }
$$

The overrun of samples was calculated according following equation [16]:

$$
\text { Overrun }(\%)=\frac{\text { weight }_{\text {mix }}-\text { Weight }_{\text {ice cream }}}{\text { Weight }_{\text {ice cream }}} \times 100 \text { (3) }
$$

\subsection{Melting properties}

Melting properties were analyzed according to Reid and Painter [17] with some modifications. Ten $g$ of ice cream samples are placed on filter paper with a diameter of 90 $\mathrm{mm}$, weight $80-103 \mathrm{~g} / \mathrm{m}^{2}$ and thickness $0.20 \mathrm{~mm}$. The wetted area $\left(\mathrm{cm}^{3}\right)$ is delineated and measured every 10,25 and 45 min using a planimeter.

\subsection{Texture profile analyse (TPA)}

The texture profile of the ice cream samples was measured using a Stable Micro Systems XT2A texture analyzer with a cylindrical sensor $(\varphi=5 \mathrm{~mm}$, area: 19.630 $\mathrm{mm}^{2}$ ). The pressure deformation rate was $1 \mathrm{~mm} / \mathrm{s}$, the deformations in the two cycles were $10 \mathrm{~mm}$, the relaxation time between cycles was $10 \mathrm{~s}$. The following texture parameters - hardness $(\mathrm{N})$, adhesiveness (N.mm), cohesiveness and gumminess $(\mathrm{N})$ were examined.

Hardness $(\mathrm{N})$ is defined as the maximum recorded force at first compression required to deform the sample. Cohesiveness is defined as the strength of internal bonds that maintain the integrity of a product. It is calculated as the ratio of the work performed (with a positive sign) during the second compression to that during the first compression. Adhesiveness (N.mm) is defined as the force (negative sign) required to separate the sample from the working body during the first compression. Gumminess $(\mathrm{N})$ is a product of the values of hardness $\times$ cohesiveness, i.e., it is the energy needed to disturb the consistency of a product in a state ready for ingestion [18].

\subsection{Sensory evaluation}

Sensory characteristics of ice cream samples such as appearance, structure and consistency, color, arome and flavor were evaluated by 15 panelists. The samples were tempered at $-15^{\circ} \mathrm{C}$ before analysis. The maximum scores of the assessed indicators are according to Bulgarian State Standard 392: 1985 [19]. 


\subsection{Statistical analysis}

The values of data are expressed as mean \pm standard deviation (SD). Data were subjected to one-way analysis of variance (ANOVA). A $p<0.05$ value indicates significantly statistical difference. Results were statistically processed using software product Statgraphics 18.0.

\section{Results and Discussion}

\subsection{Antioxidant characteristics}

Antioxidant activity is defined as the ability of a compound or composition to capture and neutralize reactive oxygen species (ROS) [20]. There are various in - vitro methods (DPPH, ABTS, FRAP, CUPRAC, ORAC) based on different mechanisms and providing information on different aspects of antioxidant activity. There is no universal method for determining "total antioxidant activity". This is due to the fact that different antioxidants may have different mechanisms of action against radicals.

In the present study, antioxidant activity was assessed by the CUPRAC method, which is based on the electron transfer mechanism. The advantages of the CUPRAC method over other in-vitro methods are the followings: the $\mathrm{pH}$ of the reaction medium is close to that of the blood (physiological $\mathrm{pH}=7.1$ - 7.2), favourable redox potential, applicability to lipophilic and hydrophilic antioxidants [21].

Table 1. Total phenolic content (TPC) and antioxidant activity, determined by CUPRAC method, of spirulina powder and ice cream samples.

\begin{tabular}{|c|c|c|}
\hline $\begin{array}{c}\text { Ice cream } \\
\text { samples }\end{array}$ & $\begin{array}{c}\text { TPC, } \\
\text { mg GAE/100g } \\
\text { DW }\end{array}$ & $\begin{array}{c}\text { CUPRAC, } \\
\text { mM TE/100 g } \\
\text { DW }\end{array}$ \\
\hline $\begin{array}{c}\text { Spirulina platensis } \\
\text { powder }\end{array}$ & $140.2 \pm 3.0$ & $1276.2 \pm 3.7$ \\
\hline IC-0 & $24.4 \pm 2.5^{\mathrm{a}}$ & $2.8 \pm 2.2^{\mathrm{a}}$ \\
\hline IC-1 & $41.5 \pm 2.0^{\mathrm{b}}$ & $34.7 \pm 5.6^{\mathrm{b}}$ \\
\hline IC-2 & $43.4 \pm 1.1^{\mathrm{b}}$ & $108.6 \pm 3.2^{\mathrm{c}}$ \\
\hline IC-3 & $43.7 \pm 0.8^{\mathrm{b}}$ & $112.9 \pm 4.1^{\mathrm{c}}$ \\
\hline
\end{tabular}

*The values are expressed as mean \pm standard deviation (SD). The values followed by different superscript letters in the same rows are statistically different $(\mathrm{p}<0.05)$. The following letter designations are used: $a, b, c, d-$ in relation to the cranberry extract concentration. n.d. not determined.

Table 1 presents the results of total phenolic content (TPC) and antioxidant activity of spirulina powder and ice cream samples. The phenolic content of Spirulina platensis powder is $140.2 \pm 3.0 \mathrm{mg} \mathrm{GAE} / 100 \mathrm{~g}$ DM. The measured values are significantly lower than the reported values of TPC of alcoholic extracts of dry spirulina (method of Folin-Ciocalteu) - $26.64 \pm 0.16 \mathrm{mg} \mathrm{GAE} / \mathrm{g}$
DW [21]; $2.93 \pm 0.06 \mathrm{mg} \mathrm{GAE} / \mathrm{g}$ DW [22]. The content of phenolic compounds in Spirulina platensis is strongly influenced by inherent and external factors such as microalgae origin, grow conditions [23], methods of treatment and storage conditions [24]. The presence of various growth and production factors explains the wide variations in the values of TPC in Spirulina platensis reported by researchers.

Regarding TPC, insignificant statistical differences ( $\mathrm{p}$ $>0.05$ ) were found between the ice cream samples enriched with spirulina powder (Table 1). On the other hand, the spirulina concentrations from $0.5 \%$ to $1.5 \%$ (used for the present research) leads to a significant increase in the TPC in the range of $70 \%-79 \%$ compared to the control sample.

The results of antioxidant activity presented in Table 1 showed that the use of spirulina leads to a significant increase in antioxidant activity from $2.8 \pm 2.2 \mathrm{mM} \mathrm{TE} / 100$ g DW (control sample) to $112.9 \pm 4.1 \mathrm{mM} \mathrm{TE} / 100 \mathrm{~g} \mathrm{DW}$ for ice cream with $1.5 \%$ spirulina (IC-3). For ice cream samples with spirulina concentrations of $1.0 \%$ and $1.5 \%$, no significant differences $(p>0.05)$ were registered between their antioxidant activity, but lower $(\mathrm{p}<0.05)$ values (mM TE/100 g DW) were observed for sample IC1.

The positive correlation between the content of phenolic compounds and the antioxidant activity of natural plant sources is well known. The antioxidant activity of phenolic compounds is related to their chemical structure. which gives them strong reducing properties to reactive oxygen species (ROS), as well as in the decomposition of peroxides [25].

Although the TPC content between the experimental samples supplemented with spirulina was statistically indistinguishable $(\mathrm{p}>0.05)$, a significant difference $(\mathrm{p}<$ 0.05 ) was found in terms of antioxidant activity. This could be explained with the present of another biologically active group with antioxidant properties in spirulina as the pigments: chlorophylls, carotenoids and phycocyanin [26].

\subsection{Quality characteristics}

\subsubsection{Chemical parameters}

The effect of Spirulina plantensis powder on the physicochemical parameters of ice cream samples is presented in Table 2.

In terms of $\mathrm{pH}$, no significant differences in values were observed between samples.

The titratable acidity increased with increased concentration of added spirulina - from $16^{\circ} \mathrm{T}$ (IC-0) to $20^{\circ} \mathrm{T}$ (IC-3), respectively. Malik et al. [27] found similar changes in titratable acidity with increasing spirulina concentration $(0.075 \%, 0.15 \%, 0.23 \%$ and $0.3 \%)$ in the ice cream mixture. This tendency could be explained by the increased buffer capacity of the ice cream mixture with Spirulina platensis, which lead to an increase in protein and mineral content. 
An increase in protein and dry matter content of samples supplemented with spirulina compared to those of control sample was observed. (Table 2).

A significant difference was found in the protein content of the control sample (IC-0) and the samples with spirulina. An increase in proteins from 3.2\% (IC-0) to $3.8 \%$ was reported for the IC-3 sample (Table 2). Agustini et al., (2016) [9] reported similar results for increasing the protein content in the enrichment of ice cream with dry spirulina at a concentration of $0.6 \%$ and $1.2 \%$. The increase in protein content is due to the relatively high content of phycocyanin (the main protein) in spirulina.

\subsubsection{Overrun}

Overrun is created by incorporation of air during the freezing to increase the mixture volume.

The quality of ice cream is influenced by the percentage of overrun [28]. The results for samples' overrun are presented in Table 2.

Table 2. Physicochemical parameters of ice cream enriched with Spirulina plantensis powder (concentration 0,5\%, 1,0\% and $1.5 \%$ ) and ice cream without spirulina addition.

\begin{tabular}{|c|c|c|c|c|}
\hline & \multicolumn{4}{|c|}{ Ice cream samples } \\
\hline & IC-0 & IC-1 & IC- 2 & IC-3 \\
\hline TA, $^{\circ}$ T & $16 \pm 0.1$ & $17 \pm 0.1$ & $18 \pm 0.2$ & $20 \pm 0.1$ \\
\hline pH & $6.7 \pm 0.01$ & $6.6 \pm 0.02$ & $6.6 \pm 0.01$ & $6.7 \pm 0.01$ \\
\hline $\begin{array}{c}\text { Proteins, } \\
\%\end{array}$ & $3.2 \pm 0.1$ & $3.6 \pm 0.12$ & $3.7 \pm 0.1$ & $3.8 \pm 0.1$ \\
\hline $\begin{array}{c}\text { DM, \% } \\
\text { D\% }\end{array}$ & $33.8 \pm 0.2$ & $34.9 \pm 0.1$ & $35.3 \pm 0.2$ & $36.3 \pm 0.3$ \\
\hline $\begin{array}{c}\text { Overrun, } \\
\%\end{array}$ & $30.6 \pm 4.4$ & $34.7 \pm 5.8$ & $36.3 \pm 3.3$ & $48.3 \pm 6.4$ \\
\hline
\end{tabular}

${ }^{*}$ TA - titratable acidity; DM - dry matter. The values of the data are expressed as means \pm standard deviation (SD)

A significant increase in overrun was reported in the experimental samples with spirulina compared to the control sample. A slight change in overrun values was measured between the samples with a spirulina concentration of $1 \%$ and $1.5 \%(34.7 \pm 5.8 \%$ and $36.3 \pm$ $3.3 \%$, respectively), while a more significant increase by about $34 \%$ was determined between a sample of $0.5 \%$ and $1.5 \%$ spirulina. Spirulina could be acting as a stabilizer. This is due to great foaming and emulsifying capacity of fat and protein contents of spirulina which helps in formation and stabilization of dispersed gas i.e., incorporated air. Spirulina has been reported to have an emulsifying capacity of $1.13 \mathrm{ml}$ fat $/ \mathrm{g}$ protein, foam capacity of $207 \%$ and $27 \%$ stability of foam [29].

\subsubsection{Melting resistance}

Fig. 1 presents the results of melting resistance of ice cream samples.

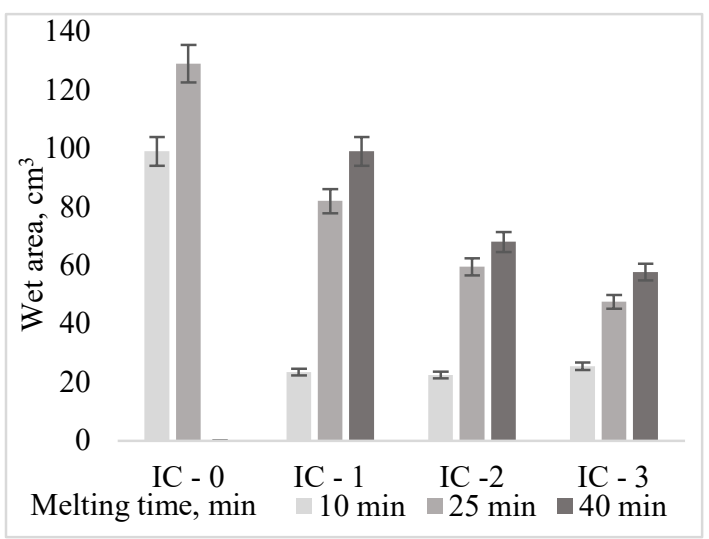

Fig. 1. Melting resistance of ice cream samples without Spirulina (IC-0) and supplemented with spirulina at concentration $0.5 \%$ (IC-1), $1 \%$ (IC-2) and $1.5 \%$ (IC-3).

The control sample showed the largest wetted area $\left(129 \mathrm{~cm}^{3}\right)$ and the shortest melting time $(25 \mathrm{~min})$ compared to the others spirulina samples. The highest melting resistance was found in sample IC-3 - for a period of $40 \mathrm{~min}$, the wetted area was $57.7 \mathrm{~cm}^{3}$. Meltdown property is attributed to water holding capacity and protein content [30]. Proteins of spirulina act as an emulsifier [31], stabilizing the fat drops and air bubbles and contribute to improved meltdown property.

\subsubsection{Texture profile analysis}

The determination of the product texture includes an assessment of the structural - mechanical properties such as hardness, adhesiveness, cohesiveness, gumminess. Texture parameters largely determine the quality characteristics of the product and correlate with sensory evaluation of indicators as consistency and structure [32].

The values of the studied textural indicators of the ice cream samples are presented in Table 3. The control sample was estimated with the highest values in terms of hardness $(13.70 \pm 1.0 \mathrm{~N})$, while in the samples with spirulina no statistically significant difference was found $(p>0.05)$. According to reported results $[33,34]$ on the rheological properties of ice cream, the hardness is inversely proportional to the fat content and the overrun (\%) i.e., low - fat ice creams and those with a relatively low percentage of incorporated air have a higher hardness.

The relatively low percent of overrun (Table 2 ) could be the reason for the higher hardness of the control sample compared to the hardness of the spirulina ice cream samples. With regard to the cohesiveness, all four samples showed statistically significant differences in the measured values $(\mathrm{p}<0.05)$, which can be presented in the following order: IC $-0>$ IC $-1>$ IC $-2>$ IC -3 . These results are in accordance with the data on the overrun (Table 2) in ice cream samples, which leads to a decrease in their density and respectively their homogeneity.

A similar profile is established by the gumminess index $(\mathrm{N})$, which is expected taking into account the 
measurement of the highest values for both parameters (hardness and cohesion) included in the determination of gumminess.

Regarding the adhesion of the ice cream samples (N.mm) it was found that the increase of spirulina concentration from $0.5 \%$ to $1.5 \%$ does not lead to a significant change $(p>0.05)$, while such is found between the control sample and that with $1.5 \%$ spirulina $(\mathrm{p}<0.05)$ (Table 3).

\subsection{Sensory analysis}

The results obtained from the sensory analysis of ice cream samples show that the addition of spirulina has a significant effect on the color and flavor characteristics.

The IC-1 sample was estimated as the most preferred between the spirulina samples, where the highest scores were given in terms of appearance and consistency (structure) (Fig. 2).

The addition of spirulina to the ice cream mixture led to higher scores on the structure and consistency, but in terms of color there was a preference for the control

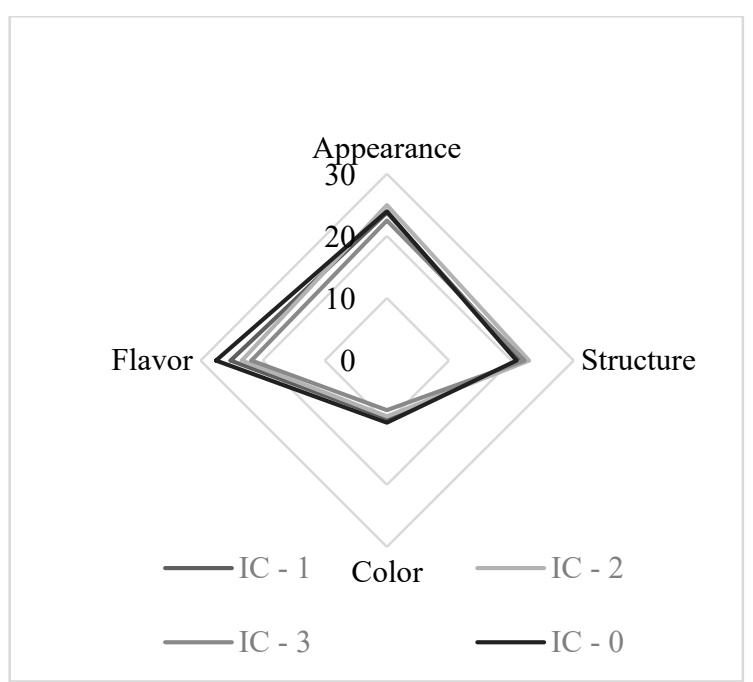

Fig. 2. Sensory evaluation of ice cream samples.

sample produced without the addition of the natural colorant - Spirulina platensis

Table 3. Texture parameters of ice cream samples without Spirulina (IC- 0 ) and supplemented with spirulina at concentration $0.5 \%$ (IC-1), 1\% (IC-2) and 1.5\% (IC-3).

\begin{tabular}{|c|c|c|c|c|}
\hline Ice cream sample & Hardness, $\mathbf{N}$ & Cohesiveness & Adhesiveness, N.mm & Gumminess, N \\
\hline IC-0 & $13.70 \pm 1.0^{\mathrm{b}}$ & $0.55 \pm 0.08^{\mathrm{d}}$ & $-1.75 \pm 0.18^{\mathrm{b}}$ & $6.23 \pm 0.58^{\mathrm{d}}$ \\
\hline IC-1 & $12.00 \pm 1.3^{\mathrm{a}}$ & $0.30 \pm 0.04^{\mathrm{c}}$ & $-1.99 \pm 0.20^{\mathrm{a}}$ & $4.11 \pm 0.56^{\mathrm{c}}$ \\
\hline IC-2 & $11.97 \pm 1.2^{\mathrm{a}}$ & $0.22 \pm 0.03^{\mathrm{b}}$ & $-2.25 \pm 0.14^{\mathrm{ab}}$ & $2.66 \pm 0.34^{\mathrm{b}}$ \\
\hline IC-3 & $10.95 \pm 1.2^{\mathrm{a}}$ & $0.16 \pm 0.01^{\mathrm{a}}$ & $-3.03 \pm 1.81^{\mathrm{a}}$ & $1.84 \pm 0.24^{\mathrm{a}}$ \\
\hline
\end{tabular}

${ }^{*}$ The values are expressed as mean \pm standard deviation (SD). The mean values followed by different superscript letters in the same column are statistically different $(\mathrm{p}<0.05)$.

Similar preferences were registered for the sensory indicator of flavor and aroma of ice cream. Panelists established the presence of an atypical flavor that spirulina imparts, despite the added mint flavor.

\section{Conclusion}

The overall results showed that the fortification of ice cream with Spirulina platensis led to increased antioxidant capacity of final product.

Moreover, Spirulina platensis addition significantly influenced the quality characteristics of ice cream inducing the formation of high overrun and enhanced melting point.

Texture profile of Spirulina samples differed with lower hardness, cohesiveness and gumminess. However, panelists gave higher score for the structure and consistency of that samples compared to those of control sample prepared without Spirulina.

Acknowledgements: The present research was financially supported by the Science Fund at the University of Food Technology - Plovdiv, Bulgaria (Project 01/20-H).

\section{References}

1. S. Gunes, S. Tamburaci, M.C. Dalay, I.D. Gurhan, Pharm. Biol. 55, 182-183 (2017)

2. J.D.C. Ores, M.C.A. Amarante, S.J. Kalil, Bioresour Technol. 219, 219-227 (2016)

3. A.A. Nuhu, J. Mar. Biol. 79, 389-392 (2013)

4. Q.Wu, L. Liu, B. Klímová, D. Wan, K. Kuca, Arch. Toxicol. 90, 1817-1840 (2016)

5. L. D. S. Uebel, J. A. Costa, A. C. Olson, M. G. D. Morais, Br. J. Chem. Eng. 36, 51-63 (2019)

6. A.B. García, E. Longo, R. Bermejo, J. Appl. Phycol. 33, 3059-3070 (2021).

7. M.C.A. de Amarante, A. Braga, L. Sala, S. Kalil, Food Res. Int. 137, 109602 (2020)

8. V.P. Barros de Medeiros, W.K.A da Costa, R.T. da Silva, T.C. Pimentel, M. Magnani, Crit. Rev. Food Sci. Nutr. 5, 1-22 (2021)

9. T.W. Agustini, W.F. Máruf, M. Suzery, S. Hadiyanto, J. Teknol. 74, 245-251 (2016)

10. Z. Khan, P. Bhadouria, P.S. Bisen, Curr. Pharm. Biotechnol. 6, 373-379 (2005)

11. A. Kulshreshtha, A.J. Zacharia, U. Jarouliya, P. Bhadauriya, G.B. Prasad, P.S. Bisen, Curr. Pharm. Biotechnol. 9, 400-405 (2008) 
12. R. Deng, T.-J. Chow, Cardiovasc. Ther. 28, e33-e45 (2010)

13. P.D. Karkos, S.C. Leong, C.D. Karkos, N. Sivaji, D.A. Assimakopoulos, Evid. Based Compl. Alternat. Med. 1-4, eCAM (2008)

14. S. Noorannisa, N. Ekantari, Web of Conf. 147, 03007 (2020)

15. I. Ivanov, R. Vrancheva, A. Marchev, N. Petkova Y. Aneva, P. Denev, G. Georgiev, I. Pavlov, Int. J. Curr. Microbiol. App. Sci. 3, 296 (2014)

16. I. Martinou-Voulasiki, G. Zefiridis, J. Food Sci. 55, 703-707 (2004)

17. W.H.E Reid, W. E. Painter, Miss. Agric. Exp. Sta. Bull. 185, 43-56 (1933)

18. A. Salvador, S.M. Fiszman, J. Dairy Sci. 87, 40334041 (2004)

19. Bulgarian State Standard 392: 1985. Ice-cream. General requirements (BIS, Sofia, 1985)

20. D. Kirkova, S. Statkova-Abeghe, M. Docheva, Y. Stremski, Sci. Works Union Scien. Bulg. - Plovdiv, Ser. C. Techn. Technol. 17, 202-208 (2019)

21. R. Apak, K. Güçlü, M. Ozyürek, S.E. Karademir, M. Altun, Free Radic. Res. 39, 949-961 (2005)

22. J. Hidayati, E. Yudiati, D. Pringgenies, D. Oktaviyanti, A. Kusuma, E3S Web of Conf. 147, 03012 (2020)

23. D. A. Marrez, M. M. Naguib, Y. Y. Sultan, Z. Y. Daw, A. M. Higazy, Inter. J. Adv. Res. 1, 951-961 (2013)

24. T. Papalia, R. Sidari, M. Panuccio, Molecules. 24, 2810 (2019)

25. C.M. Thayag, Y. Lin, C. Lin, C. Liou, J. Chen, Fish Shellfish Immun. 28, 764-773 (2010)

26. A. Ranga Rao, R. Raghunath Reddy, V. Baskaran, R. Sarada, G. Ravishankar, J. Agric. Food Chem. 58, 8553-8559 (2010)

27. P. Malik, C. Kempanna, A. Paul, International J. Food Nutr. Sci. 2, 44-50 (2013)

28. Q. A. Syed, J. Nutr. Health Food Eng. 8, 422-435 (2018)

29. R.K. Robinson., A.B. Carl, D.P. Pradip, Encyclopedia of food microbiology (Academic Press, Amsterdam-Boston-Heidelberg-London-New YorkOxford-Paris-San Diego-San Francisco-SingaporeSydney-Tokyo, 2000)

30. R. P. Sofijan, R. W. Hartel, Int. Dairy J. 14, 255-262 (2004)

31. A.A. El-Rahman, S.A. Madkor, F.S. Ibrahim, Int. J. Dairy Sci. 80, 1926-1935 (1997)

32. N. Ben Halima, M. Borchani, I. Fendri, B. Khemakhem, D. Gosset, P. Baril, S. Abdelkafi, Int. J. Biol. Macromol. 72, 1213-1221 (2015)

33. A. Akalın, C. Karagozlu, G. Unal, Eur. Food Res. Technol. 227, 889-895 (2008)

34. G. El-Nagar, G. Clowes, C.M. Tudorica, V. Kuri, C.S. Brennan, Int. J. Dairy Technol. 55, 89-93 (2002) 